\title{
Growth hormone responses to hp GRF 1-44 amide, bromocriptine and stress in acromegaly are correlated
}

\author{
P.E. Belchetz \\ Department of Medicine, The University of Liverpool, P.O. Box 147, Liverpool L69 3BX, UK
}

\begin{abstract}
Summary: The results of testing growth hormone (GH) reserve using human pancreatic growth hormone-releasing factor 1-44 amide (hp GRF 1-44 amide) have been compared with the GH responses in a variety of other dynamic tests in seven acromegalic patients. The GH release following hp GRF 1-44 amide correlated with the GH suppression following bromocriptine, but showed an inverse correlation with the GH release following stress tests (insulin-induced hypoglycaemia/glucagon). There was no correlation between the GH responses in these three tests and any of the other tests: TRH, GnRH and glucose. A hypothesis is proposed to explain these findings on the basis of varying degrees of GH secretion from adenomatous and normal pituitary somatotrophs in acromegaly.
\end{abstract}

\section{Introduction}

In addition to basal hypersecretion of growth hormone (GH), acromegalics frequently display aberrant $\mathrm{GH}$ responses to various stimuli. These include failure of suppression following glucose, failure of stimulation during insulin-induced hypoglycaemia, paradoxical stimulation with thyrotrophin releasing hormone (TRH) and, less often, gonadotrophin releasing hormone (GnRH) and suppression of GH secretion with bromocriptine. As the vast majority of acromegaly is due to clearly identifiable pituitary adenomas these findings are commonly attributed to abnormal receptors on the tumorous somatotrophs. Very rare cases of ectopic secretion of growth hormone releasing factors (GRFs) from extra pituitary tumours led to the isolation and characterization of a family of GRFs from pancreatic islet cell tumours in two patients ${ }^{1,2}$ which are almost certainly identical to authentic human hypothalamic GRFs. ${ }^{3}$ Notwithstanding the lack of any obvious aetiological relationship between GRF and acromegaly in most cases, ${ }^{4}$ the findings in other tests of GH secretion mentioned above prompted a study of GRF-induced GH secretion in acromegaly and its comparison to responses in other standard tests. Some of these findings have been presented in preliminary form elsewhere. ${ }^{5}$

Correspondence: P.E. Belchetz, M.A., M.D., M.Sc., F.R.C.P

Accepted: 22 September 1986

\section{Materials and methods}

Seven acromegalic patients were studied aged 34 to 63 years. Five were previously untreated (four men and one women) while one man and one woman were studied who had persistently excessive GH secretion following transsphenoidal surgery but who had otherwise received no therapy.

The test protocols which were performed in random order at least 24 hours apart were: (1) human pancreatic (hp) GRF 1-44 amide $50 \mu \mathrm{g}$ i.v: blood samples at 30 minute intervals for 2 hours; (2) TRH $200 \mu \mathrm{g}$ i.v:blood samples at 0, 20, 60 minutes; (3) glucose 50 g.p.o.:blood samples at 30 minute intervals for 2 hours; (4) bromocriptine $2.5 \mathrm{mg}$ p.o.:blood samples at hourly intervals for up to 6 hours. These tests were conducted in all seven patients. (5) GnRH $100 \mu \mathrm{g}$ i.v: blood samples at $0,20,60$ minutes performed in six subjects. (6) Stress tests: (a) insulin in $0.3 \mathrm{U} / \mathrm{kg}$ i.v.: blood samples at $0,30,45,60,90,120$ minutes, performed in five subjects; (b) glucagon $1.5 \mathrm{mg}$ s.c. blood samples at $0,90,120,150,180,210,240$ minutes, performed in one patient with longstanding epilepsy.

Plasma was rapidly separated after sampling and stored at $-20^{\circ} \mathrm{C}$ until assay. Samples from each test for each subject were placed in the same assay and measured in duplicate. The sensitivity of the GH assay was $0.4 \mathrm{mU} / 1$ and the intra-assay coefficient of variation less than $10 \%$.

The hp GRF 1-44 amide was manufactured by solid phase peptide synthesis by Bachem Inc., California, and supplied by Universal Biologicals, Cambridge, 
Table I GH responses (mU/l) to hp GRF 1-44 amide $50 \mu \mathrm{gi.v.}$

\begin{tabular}{cccrrrrrr}
\hline & & & \multicolumn{6}{c}{ Time (minutes) } \\
Subject & Age (y) & Sex & 0 & 30 & 60 & 90 & 120 \\
\hline $1^{*}$ & 38 & F & 10.1 & 12.4 & 11.8 & 12.5 & 17.6 \\
2 & 34 & F & 22 & 39 & 30 & 36 & 54 \\
3 & 63 & M & 120 & 220 & 190 & 160 & 280 \\
4 & 36 & M & 120 & 155 & 135 & 130 & 110 \\
5 & 55 & M & 55 & 55 & 84 & 96 & 61 \\
$6^{*}$ & 58 & M & 42 & 41 & 36 & 47 & 53 \\
7 & 42 & M & 45 & 48 & 42 & 50 & 58 \\
\hline
\end{tabular}

*Post transsphenoidal surgery.

UK. It was aliquoted and lyophilized under sterile conditions and dissolved in $2 \mathrm{ml} 0.9 \% \mathrm{NaCl}$ immediately before use. Since wide variation in GH responses was seen in some tests, the results were analysed by the Spearman rank correlation coefficient. Also because changes in GH varied widely as well as and independently of baseline values, the findings have been expressed as absolute concentrations rather than percentages of basal values.

\section{Results}

All seven subjects showed increases in GH following $50 \mu \mathrm{g} \mathrm{hp} \mathrm{GRP} \mathrm{1-44} \mathrm{amide} \mathrm{i.v.} \mathrm{(Table} \mathrm{I).} \mathrm{In} \mathrm{four} \mathrm{cases}$ there was a minor early peak at 30 minutes and a later larger peak at 120 minutes, in two cases single late peaks at 90 and 120 minutes respectively and in one case only a single early peak at 30 minutes.

The findings in all six tests with respect to the maximum change in GH concentration observed are summarized in Table II. It should be stated that the minimum GH concentration following oral bromocriptine occurred at 2 hours or more after the dose.

The peak increment in GH post-hp GRF 1-44 amide correlated with the maximum decrement post-

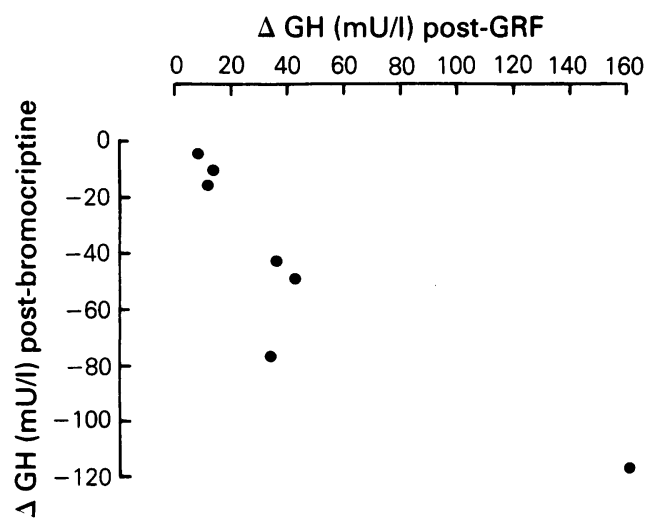

Figure 1 The relationship between the maximum increment in GH after hp GRF $1-44$ amide $50 \mu \mathrm{g}$ i.v. and the maximum decrement in $\mathrm{GH}$ after bromocriptine $2.5 \mathrm{mg}$ p.o.

bromocriptine $(P=0.014$, Spearman's rank correlation coefficient) (Figure 1). There was an inverse correlation between the peak increments in GH posthp GRF 1-44 amide and 'stress' (insulin-induced hypoglycaemia/glucagon) (Figure 2$)(P<0.01)$. No other correlations were demonstrable.

\section{Discussion}

This study disclosed variable GH responses to $50 \mu \mathrm{g} \mathrm{hp} \mathrm{GRF} 1-44$ amide in acromegaly as we previously demonstrated with the same dose in normal $\overrightarrow{\vec{F}}$ volunteers. ${ }^{6}$ In contrast to those findings, however, in six out of seven acromegalics the peak level was attained later than in normal subjects, although there was a minor early peak in four subjects. The GH response to TRH encompassed the greatest range, 3 from nil to greater than $1234 \mathrm{mU} / 1$ but these changes showed no relationship to those seen in other tests in contrast to the earlier suggestions of a correlation with suppression after bromocriptine.

Table II Maximal changes in GH (mU/l) during dynamic tests of $\mathrm{GH}$ secretion.

\begin{tabular}{|c|c|c|c|c|c|c|}
\hline Subject & hp GRF 1-44 amide & $T R H$ & $G n R H$ & $G T T$ & ITT/Glucagon* & Bromocriptine \\
\hline 1 & 7.6 & 0 & 16.5 & -2.8 & N.D. & -4.4 \\
\hline 2 & 32 & 70 & -21 & 35 & 28 & -76 \\
\hline 3 & 160 & $>1234$ & N.D. & -31 & -47 & -116 \\
\hline 4 & 35 & 10 & 5 & -32 & $20^{*}$ & -42 \\
\hline 5 & 41 & 9 & 18 & 5 & 14 & -49 \\
\hline 6 & 11 & 30 & 7 & 3 & 88 & -15 \\
\hline 7 & 13 & 325 & 2 & 8 & 51 & -9.2 \\
\hline
\end{tabular}

N.D.: test not done. TRH = thyrotrophin releasing hormone; GnRH = gonadotrophin releasing hormone; GTT = glucose tolerance test; ITT $=$ insulin tolerance test. 


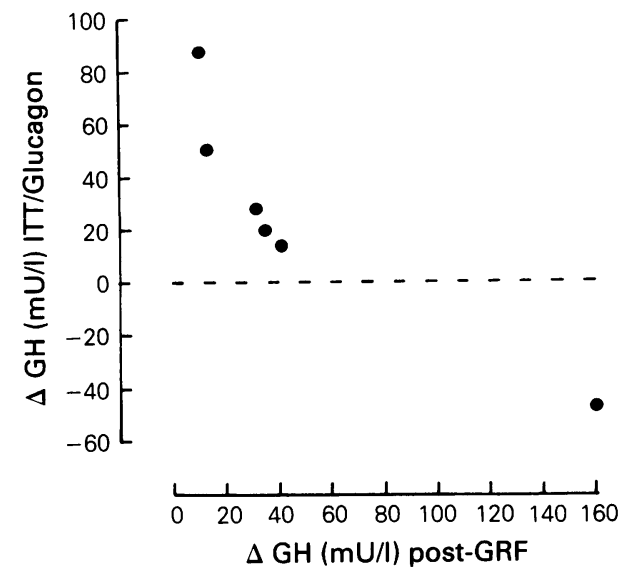

Figure 2 The relationship between the maximum increment in GH after hp GRF 1-44 amide $50 \mu \mathrm{g}$ i.v. and the maximum change (increment or decrement) following 'stress' tests:insulin-induced hypoglycaemia (ITT) or glucagon $1.5 \mathrm{mg} \mathrm{s.c.}$

The absence of a correlation between the changes in GH following hp GRF 1-44 amide and oral glucose is an extension of our previous findings in two acromegalics and in contradiction of the claims by Wood and colleagues. ${ }^{8}$ Our findings, insofar as the tests and patients are comparable, are not dissimilar to those reported elsewhere. ${ }^{9,10,11,12}$ There is a striking discordancy between our findings suggesting that the greater the release of GH post-hp GRF 1-44 amide, the greater suppression after bromocriptine and the opposite of the assertion by Chiodini et al. ${ }^{13}$ Their relationship was considerably weaker but was based on the study of 35 patients. Their data are expressed as percentage changes but reanalysing it in terms of absolute concentration differences merely abolishes the pattern and does not reverse it. They do not say if any patient had received any form of treatment except seven who had previously received bromocriptine. The single difference between the present study and most others published is that of dosage. The use of a submaximal dose (50 $\mu \mathrm{g}$ as opposed to $100 \mu \mathrm{g})$ might allow subtle differences in secretion to be observed ( $\mathbf{S}$. Reichlin, personal communication).

The following hypothesis is proposed to account for the observations made in this study. The normal pituitary somatotrophs secrete $\mathrm{GH}$ under the dual control of hypothalamic GRF and somatostatin which in turn are influenced by various neural inputs, including stress, and mediated by a variety of neurotransmitters, including dopamine; exogenous GRF largely reaches the pituitary by the portal vessels and bromocriptine largely acts centrally (Figure 3a). The adenomatous tissue in acromegaly is partly autonomous and often has a significant blood supply from capsular and trabecular vessels. Hypothalamic GRF production in rats is reduced by intracisternal $\mathrm{GH}$, suggesting a short feedback loop. ${ }^{14}$ The exogenous administration of hp GRF 1-44 amide tends to produce an early peak of GH from normal pituitary cells - reached via portal vessels and reduced in height
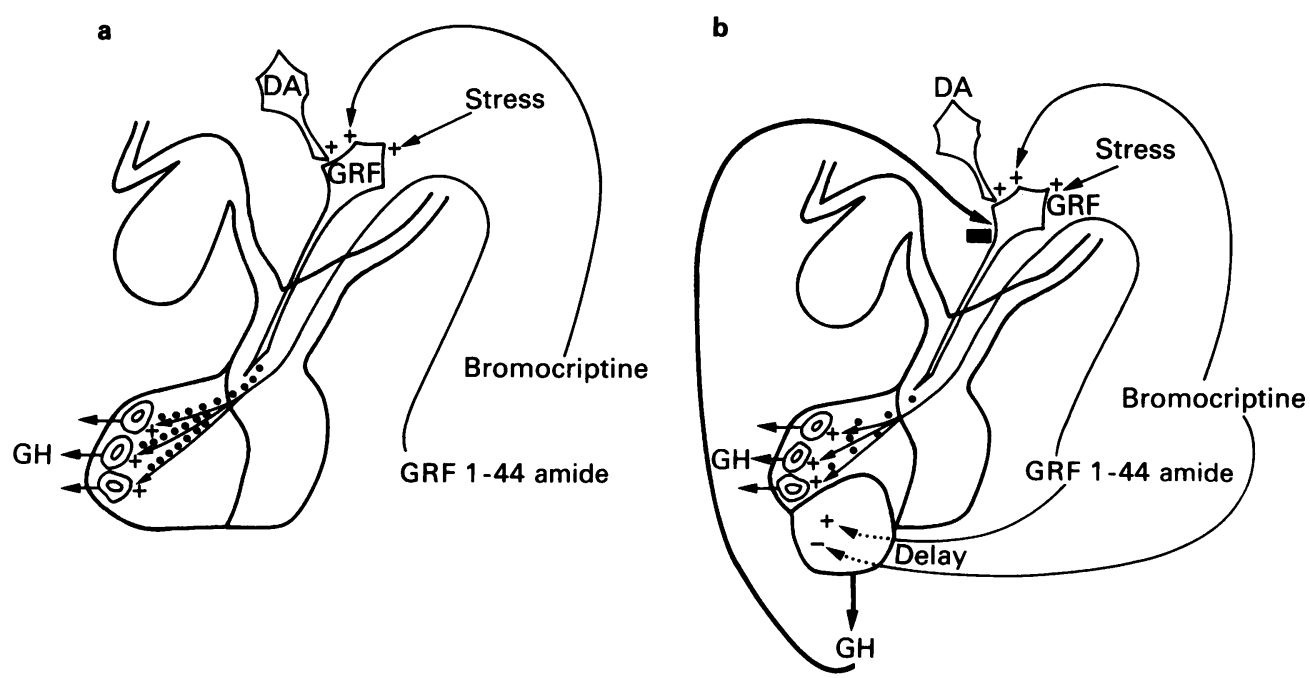

Figure 3 Model for the endogenous and exogenous control of GH secretion (a) from the normal anterior pituitary, (b) in acromegaly due to hypersecretion of $\mathrm{GH}$ from a pituitary adenoma - which (i) exerts a negative feedback action on endogenous GRF production and (ii) is partly reached in a delayed fashion, by non-portal blood vessels. 
because of relatively suppressed activity induced by the feedback inhibition of endogenous GRF by GH from the adenoma. This central inhibition of endogenous GRF secretion is also responsible for the relatively obtunded 'stress release of $\mathrm{GH}$ and the failure of bromocriptine to act centrally to release $\mathrm{GH}$. Instead there is direct action on exogenous hp GRF 1-44 amide and bromocriptine on the adenomatous tissue, in part poorly penetrated and reached by non-portal vessels. Hence the response from the adenoma to

\section{References}

1. Guillemin, R., Brazeau, P., Bohlen, P., Esch, F., Ling, N. \& Wehrenberg, W.B. Growth hormone-releasing factor from a human pancreatic tumour that caused acromegaly. Science 1982, 218: 585-587.

2. River, J., Spiess, J., Thorner, M. \& Vale, W. Characterization of a growth hormone-releasing factor from a human pancreatic islet tumour. Nature 1982, 300: 276278.

3. Bohlen, P., Brazeau, P., Bloch, B., Ling, N., Gaillard, R. \& Guillemin, $R$. Human hypothalamic growth hormone releasing factor (GRF): evidence for two forms identical to tumor derived GRF-44-NH $\mathrm{NH}_{2}$ and GRF-40. Biochem Biophys Res Commun 1983, 114: 930-936.

4. Penny, E.S., Penman E., Price, P., Rees, L.H., Sopwith A.M., Wass, J.A.H., Lytras, N. \& Besser, G.M. Circulating growth hormone releasing factor concentrations in normal subjects and patients with acromegaly. Br Med J 1984, 289: 453-455.

5. Belchetz, P.E. Correlation between $\mathrm{GH}$ responses to GRF 1-44 amide, stress and bromocriptine in acromegaly. Neuroendocrinology 1985. Letters 7: 79.

6. Belchetz, P.E., Weldon, S.F., Davis, J.C., Diver, M.J., Smith, C.S. \& Harris, F. Potential uses of human pancreatic growth hormone-releasing factor 1-44 amide. Clin Endocrinol (Oxf) 1984, 21: 201-208.

7. Liuzzi, A., Chiodini, P.G., Botalla, L., Silvestrini, F. \& Muller, E.E. Growth hormone $(\mathrm{GH})$ - releasing activity of TRH and GH-lowering effect of dopaminergic drugs in acromegaly: homogeneity in the two responses. J Clin Endocrinol Metab 1974, 39: 871-876.

8. Wood, S.M., Ch'ng, J.H.C., Adams, E.F., Webster, J.D., Joplin, G.F., Mashiter, K. \& Bloom, S.R. Abnormalities of growth hormone release in response to human pancreatic growth hormone releasing factor hp GRF 1-44 amide and bromocriptine are both delayed (Figure 3b). This explanation is highly speculative and requires further studies for confirmation with greater numbers of similarly treated patients.

\section{Acknowledgements}

I thank the Sub-department of Endocrine Pathology for $\overline{\bar{\omega}}$ radioimmunoassay of $\mathrm{GH}$ and $\mathrm{Mr}$ C.R. West, Sub-department of Bio-Statistics, for statistical advice.

(GRF (1-44)) in acromegaly and hypopituitarism. $\mathrm{Br}$ Med J 1983, 286: 1687-1691.

9. von Werder, K., Muller, O.A., Buchner, A., Hartl, R., Losa, M. \& Stalla, G.K. Human pancreatic growth hormone releasing factor (hp GRF): biological activity in $\mathcal{W}$ normal controls and in patients with acromegaly. Acta $\infty$ Endocrinol (Copenh) 1983, 103: (Supplement 256) 71.

10. Pieters, G.F.F.M., Smals, A.E.M., Hermus, A.R.M.M., $\stackrel{\oplus}{\rightarrow}$ Smals, A.G.H., Benraad, Th. J. \& Kloppenborg, P.W.C. 웅 Growth hormone responsiveness to human pancreatic growth hormone releasing factor in acromegaly: $D$ modulatory effects of basal hormone levels and of 0 . concomitant somatostatin administration. Clin Endocrinol (Oxf) 1984, 21: 701-707.

11. Shibasaki, T., Shizume, K., Masuda, A., Nakahara, M̊̊ Hizuka, N., Miyakawa, M., Takane, K., Demura, Hz Wakabayashi, I. \& Ling, N. Plasma growth hormon response to growth hormone-releasing factor $\overrightarrow{\mathrm{m}}$ acromegalic patients. J Clin Endocrinol Metab 1984, 58: 215-217.

12. Gelato, M.C., Merriam, G.R., Vance, M.L. et al. Effects of growth hormone-releasing factor on growth hormone secretion in acromegaly. J Clin Endocrinol Metab 1985, 60: $251-257$.

13. Chiodini, P.G., Liuzzi, A., Dallabonzana, D., Oppizzi, G. \& Verde, G.G. Changes in growth hormone (GH) secretion induced by human pancreatic $\mathrm{GH}$ releasing hormone -44 in acromegaly: a comparison with thyrotropin-releasing hormone and bromocriptine. $J$ Clin Endocrinol Metab 1985, 60: 48-52.

14. Tannenbaum, G. Interactions of GRF and somatostatin. International Symposium GH, Growth Hormone Factors, Acromegaly. Aegina, Greece. (unpublished) 